\title{
OLDER ADULTS' PREFERENCES FOR TECHNOLOGICAL NUTRITION EDUCATION
}

\author{
by
}

MARIA E. PERVERSI

B.S., Universidad del Salvador, Buenos Aires, Argentina, 2001

\begin{abstract}
A THESIS
submitted in partial fulfillment of the requirements for the degree

MASTER OF SCIENCE

Department of Human Nutrition

College of Human Ecology

KANSAS STATE UNIVERSITY

Manhattan, Kansas

2007
\end{abstract}

Approved by:

Major Professor

Valentina M. Remig, Ph.D. 


\begin{abstract}
The use of computer-based and personal assistive technology is projected to increase as the boomer generation continues to age. Technology is infiltrating and improving the lives of older adults, including their education. This study determined older adults' preferences toward the use of technology to learn about nutrition and health. The sample included 132 volunteer subjects, mostly female, white non-Hispanic, ranging in age from 65-92 years, recruited from local organizations, senior centers, churches, and senior apartments. All participants completed a newly developed, 32-item pilot tested questionnaire that included demographic and self-rated health characteristics, current use of technology, factors that motivate and/or influence attitudes and interest toward use of technology, and preferred formats and topics of interest for nutrition and health education information. The results indicated that, overall, these older adults self-rated their health as either excellent or good, and that those who were younger and among the higher income brackets and education levels were more likely to use computers than those who were older, with less income, and education levels . Findings also indicated that older adults were interested and willing to learn about technology, had positive attitudes toward it and showed a high demand for user-friendly programs and training. Finally, results show that although newsletters, magazines and television were mostly preferred by older adults, computers were also considered very helpful and were used to learn about nutrition and health information.
\end{abstract}




\section{TABLE OF CONTENTS}

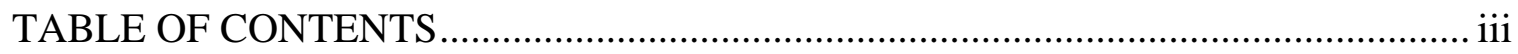

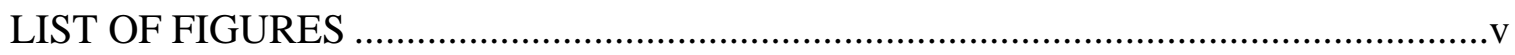

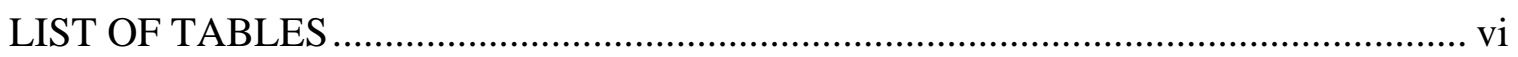

ACKNOWLEDGEMENTS ................................................................................ vii

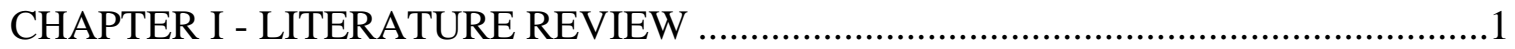

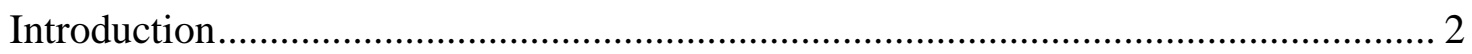

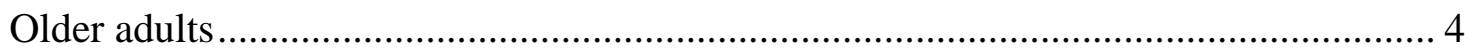

Demographic characteristics .............................................................................. 4

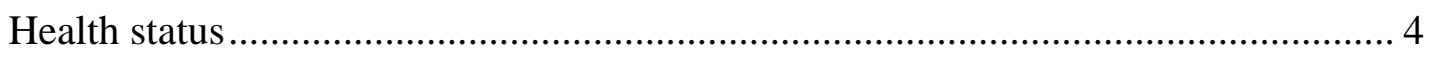

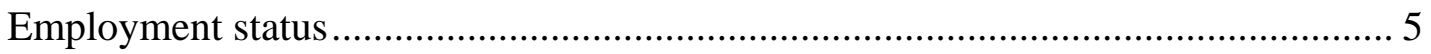

Current use of technology ............................................................................... 5

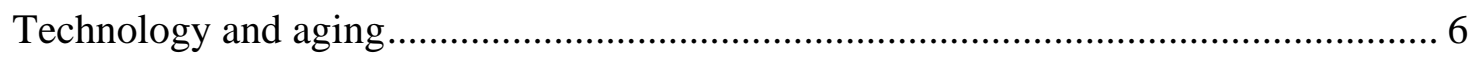

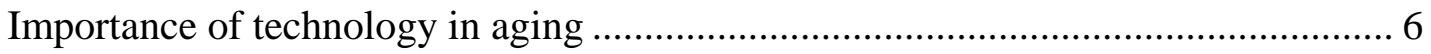

Attitudes toward computers ............................................................................... 7

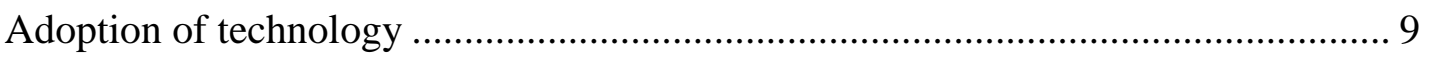

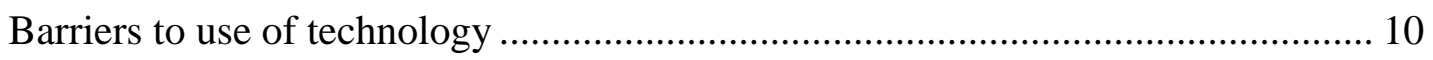

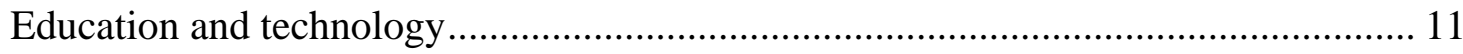

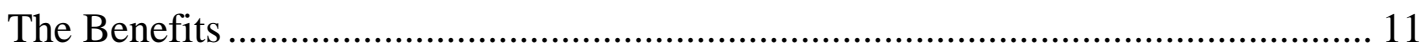

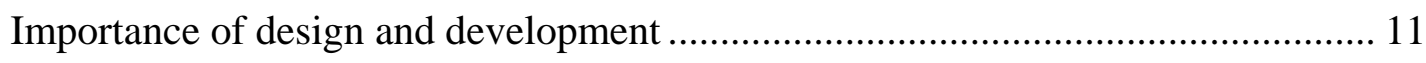

Topics and formats of preference ……………………...................................... 12

Purpose

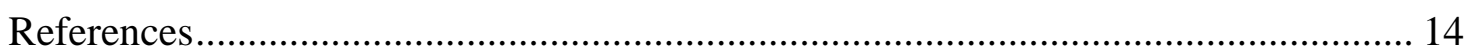

CHAPTER II -_OLDER ADULTS' PREFERENCES FOR TECHNOLOGICAL

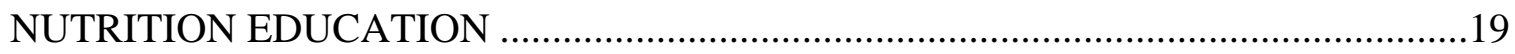

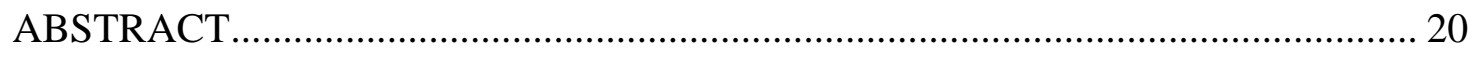

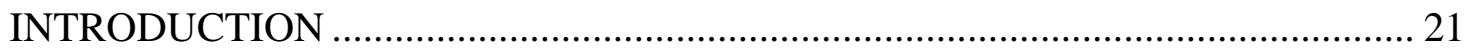

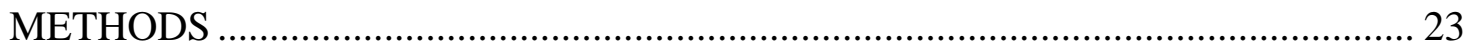

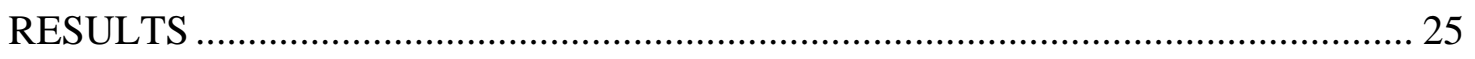




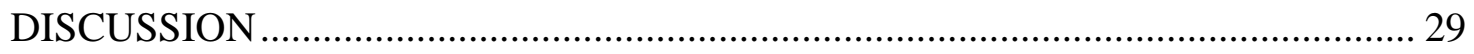

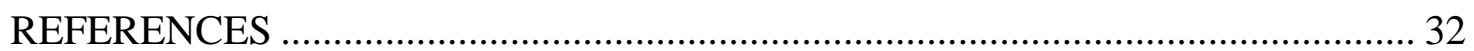

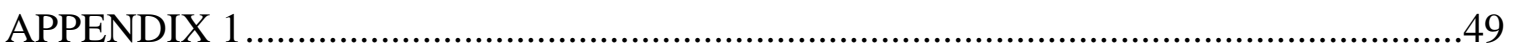

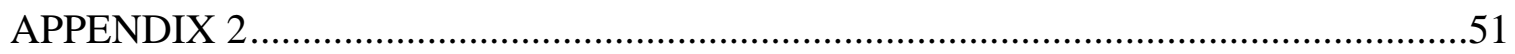

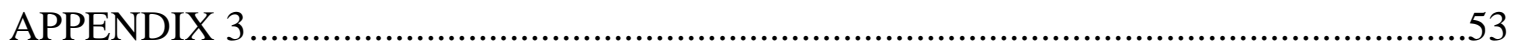




\section{LIST OF FIGURES}

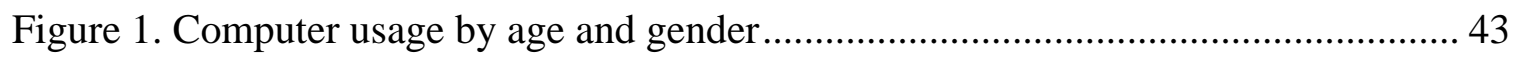

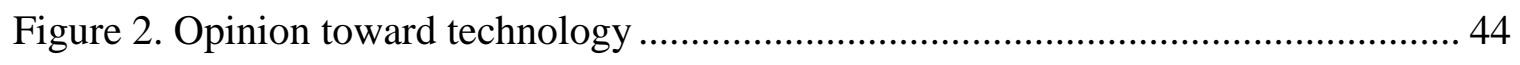

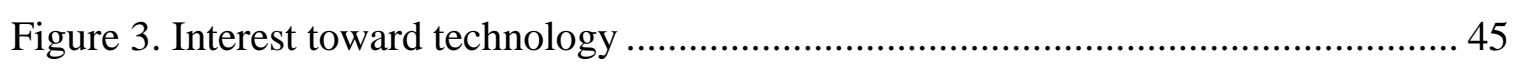

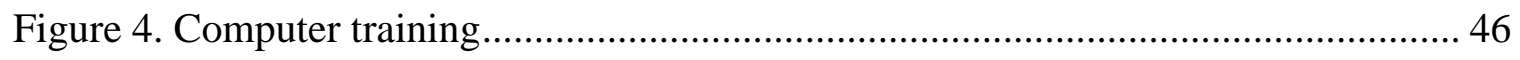

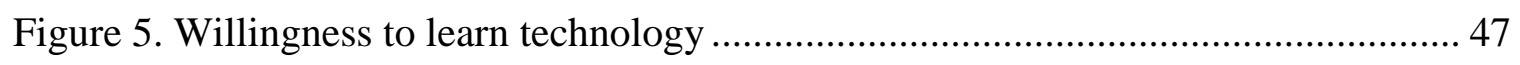

Figure 6 . Nutrition and health topics of interest among the study population................. 48 


\section{LIST OF TABLES}

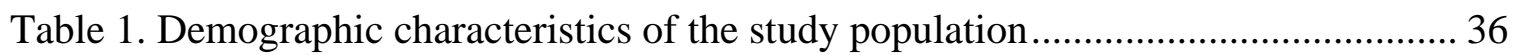

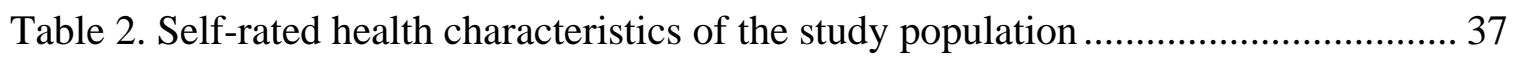

Table 3. Computer usage by gender, age group and educational level.......................... 38

Table 4. Types of technology familiar and/or used by participants.............................. 39

Table 5. Factors that influence participant's computer usage....................................... 39

Table 6. Preferred formats to learn about health education ........................................... 40

Table 7. Most used formats to learn about health education ....................................... 40

Table 8. Profile of participants who were interested in a nutrition topic ........................ 41

Table 9. Profile of participants who used the computer to look up nutrition information 42 


\begin{abstract}
ACKNOWLEDGEMENTS
In first place, I would like to express sincere appreciation to my major professor, Dr. Tina Remig, for helping me persevere and achieve the skills needed to complete this project. I am also especially grateful for her kindness and respect as a colleague.

Secondly, I would like to thank my committee members, Dr. Carol Ann Holcomb and Dr. Mark Haub for their continuous support and guidance. Thank you for sharing your knowledge and experience with me.

A special thank you goes to all my friends and faculty members in and out of the Department of Human Nutrition. Thanks for making my time at K-State not only a professional achievement but also a great personal enrichment.
\end{abstract}

Finally, sincere gratitude toward my parents and family for always allowing and encouraging me to pursue and achieve my goals. Thanks for your unconditional support. 


\section{CHAPTER I}

\section{LITERATURE REVIEW}




\section{Introduction}

With the rapid growth of the older adult population in the U.S. and the continuous advances in technology, identifying older adults' preferences and expectations for using technology and learning new information is increasingly important. In 2006, only $34 \%$ of Americans over the age of 65 used the Internet, compared to $71 \%$ of younger adults aged 50-64 '. An increase in older adults' use of technology is expected as the baby boom generation ages; several factors such as age, gender, income and education are strong predictors for use of current technologies, especially computers ${ }^{2,3}$.

Computer-based technology continues to impact our society, becoming a major component of work, environments, education, entertainment and communication ${ }^{4}$. For older adults, the influence of technology in their lives is even broader; it fosters social interaction, maintenance of autonomy, better functionality, comfort, and safety within homes ${ }^{5,6}$. The integration of technology and aging to improve the quality of life and health of older adults is defined as "gerotechnology" 2,6. The term is used frequently in the literature to explain that technology and aging have a "reciprocal influence" on one another. This means that the needs of an aging population will affect the way in which technology is designed, and at the same time, technology will improve the aging process, allowing for a better quality of life ${ }^{7}$.

Several recent studies have shown that computer-based education may improve older adults' short-term memory, daily functioning, knowledge about different health topics and attitudes toward certain food products ${ }^{8,9}$. In addition, computers can provide older adults with independence, privacy and self-paced individualized learning ${ }^{10}$.

For older adults to adopt technology however, computer programs should be designed considering their needs and motivations for use, and proper training should be made available ${ }^{2,7,11}$. Teaching and training older adults to use new technological devices and software is crucial, because as boomers age the need will rise in parallel with the average age of computer users ${ }^{3}$. Several investigators have suggested that training for older adults needs to focus on reducing the barriers faced when using computers or assistive devices, such as hearing aids or vision devices ${ }^{12,13}$. 
Although the number of research studies evaluating technology use among older adults is increasing, still limited findings about their preferences toward technology and health education have been reported. Thus, the purpose of this investigation was to add to the body of knowledge by determining older adults' preferences toward the use of technology, particularly with implications for learning about nutrition and health.

To better understand older adults and what leads their preferences toward the use of technology, general characteristics of older adults as a group is initially described, including their current use of computers and technology. Secondly, the role of technology in aging provides information about how technology impacts older adults' lives, and reports what motivates their attitudes and interest toward adoption of technology. In addition, barriers that older adults may face when using computers and/or technology are presented. Finally, because this study was oriented toward nutrition and overall health education, a brief summary of computer-based education research portrays the positive influence and/or benefits that a well-designed computer-based program may have for older adults, further influencing their preferences toward technology. 


\section{Older adults}

Because older adults are a heterogeneous and diverse population, the definition of the term "older adult" varies. Researchers generally describe three subgroups: the "young old" (ages 65-75), the "older-old" (ages 75-85), and the "oldest old" (ages 85 and older) 14 .

\section{Demographic characteristics}

According to a report from the U.S. Census Bureau, in 2003, 12.4\% (36 million) of the U.S. population was 65 and older. However, the older population is projected to double by 2030 , reaching $20 \%$ of the total U.S. population. Non-Hispanic whites accounted for nearly $83 \%$ of the older population in 2003, while Blacks, Asians and Hispanics accounted for $8 \%, 3 \%$ and $6 \%$ respectively ${ }^{15}$.

In addition, $72 \%$ of the older population had graduated from high school, $17 \%$ had at least a bachelor's degree, and a higher proportion of older men than older women had obtained the degree. Furthermore, in 2003, households maintained by older people had net worth higher than that of all other households, except for those maintained by householders between the ages of 55-64 years ${ }^{15}$.

\section{Health status}

People in the United States are reportedly living longer and healthier lives than ever before ${ }^{15}$. "The State of Aging and Health in America 2007" CDC report indicated that $39 \%$ of non-Hispanic white adults aged 65 years or older reported very good or excellent health, compared with $29 \%$ of Hispanics and $24 \%$ of non-Hispanic blacks ${ }^{16}$.

Heart disease, cancer and stroke continue to be three primary causes of death among older adults. About $80 \%$ of older adults have at least one chronic health condition, and 50\% have at least two. In addition, among all people using assistive devices, people $65+$ years of age use a majority of the mobility, hearing and vision devices ${ }^{15}$.

With national health care expenditures totaling an estimated \$1.3 trillion, the U.S. spends more on health than any other industrialized country. Of the total expenses, $65 \%$ were paid by public programs such as Medicare and Medicaid. In 2000, Medicare 
reported a cost of $\$ 222$ billion. Researchers predict however, that increased longevity is likely to have implications for the financing of the health care system.

\section{Employment status}

In general, the percentage of the population that is employed declines with age, however, the proportion of older adults (men and women) who work part-time increases with age. In 2003, $65.6 \%$ of men and 54.5\% of women aged 55-64 were employed, compared with $11.8 \%$ of men and $6.2 \%$ of women aged $70+{ }^{15}$. Projections indicate that by 2020 , when all boomers will be 55 years or older, people in the 55-64 year age group will represent $15.3 \%$ of the labor force, and those in the 65 and older age group will account for $5 \%$.

Occupations and type of employment vary by age. Older people are more likely to be engaged in alternative employment arrangements, such as being independent contractors, on-call workers, temporary help workers, and workers provided by contract firms ${ }^{15}$. In addition, the largest source of employment among older workers (65+ years) is the private sector, followed by self-employment ${ }^{15}$.

\section{Current use of technology}

The use of computer-based and personal assistive technology is projected to increase as the boomer generation, those born between 1946 and1964, ${ }^{3}$ continues to age. Over the last decade, new technology has contributed to maintaining the independence, quality of life, and well-being of older adults ${ }^{5}$. Older adults are starting to experience the benefits ${ }^{17}$ of online health searches, shopping, banking and email, which have increased among the older population ${ }^{18}$. According to a survey done at a senior website in November 2002, 72\% of older adults said they used the Internet to "stay current with news and events" ${ }^{19}$. However, this survey was limited to older adults aware of the site and who may have been more inclined to participate.

In 2004, 22\% of all Americans over age 65 were reported to use the Internet ${ }^{18}$. Currently, this percentage has increased to 33-34\% ${ }^{1}$. By the year 2010 however, it is estimated that more than $70 \%$ of all older adults will be using the Internet ${ }^{20}$, since it is becoming increasingly cost-effective and socially important to support the independence of older adults ${ }^{21,4}$. 
The percentage of older adults willing to go online increased by almost $50 \%$ between 2000 and $2004{ }^{18}$. Use of the Internet by men and women became equal in 2004 as opposed to how it was in 2000, where $60 \%$ of users were men and only $40 \%$ women. The World Wide Web is, therefore, increasingly being identified by older adults as an important source for information about health ${ }^{18}$.

Age and computer experience appear to strongly influence the use of technology and the attitudes toward it ${ }^{4}$. Some authors affirmed that older adults were more likely to have negative attitudes toward technology than their younger peers ${ }^{22}$. However, newer findings in the scientific literature indicate that the nature of computer experience (positive or negative) is what will determine older adults' self-efficacy, computer anxiety and overall attitudes when compared to the younger groups ${ }^{4}$.

According to a survey of 2,373 adult Internet users $(18+$ years $){ }^{1}$, ethnicity, income and education also influence the use of the Internet. The highest percentage of Internet users were found to be White non- Hispanics, college educated and with incomes of $\$ 50,000$ and above. ${ }^{1}$ Training also influences computer usage, because it allows to build up confidence in people's abilities ${ }^{4}$. The Microsoft Corporation suggests that providing older adults with computer training will enable them to increase their computer use $^{3}$.

As baby boomers age, it is anticipated that they will be more computer literate and dependent on technology than the current older adults. They will have experienced and sustained computer usage earlier in life ${ }^{2}$. Today's older adults increasingly need to become computer literate, receive adequate training, and have the ability to retain these skills ${ }^{23,24}$.

\section{Technology and aging}

\section{Importance of technology in aging}

Today, technology is being introduced into everyday services such as banking, health care, and transportation. It also plays a key role in education, entertainment, home safety and communication, affecting the aging population ${ }^{2}$. Technology may also influence the delay of retirement age, offering accommodation for disabilities, and enhancing peak productivity of this group ${ }^{2}$. In addition, technology has a profound 
impact on older adults' lives by providing independence through the development of new assistive and educational programs ${ }^{2}$.

A study by Mynatt et al. reports that technology in the home will eventually help older adults further maintain their independence by promoting aging in place. Examples of this include performing activities of daily living (ADLs), such as bathing, eating and/or dressing, as well as helping with instrumental activities of daily living (IADLs) such as doing laundry, taking medication, and/or cooking ${ }^{12}$.

A new relevant term being used in the literature is "gerotechnology". Gerotechnology studies the interaction of elderly people with technological products and the built environment. It integrates the study of technology and aging in order to improve the quality of life and health of older adults, providing new opportunities from an educational point of view ${ }^{6}$.

Having realized the importance of technology for older adults, private foundations and organizations are now providing information supporting the use of technology. For example, the SeniorNet website encourages practice using different computer components, such as a mouse, or tutorials and demonstrations of proper computer procedures ${ }^{19}$. However, to better understand the preferences of older adults toward the use of technology, more information about attitudes toward computers and technology is needed.

\section{Attitudes toward computers}

Attitudes tend to guide behavior and may influence willingness to accept and use technology ${ }^{22}$. Older adults are reported to have a present-oriented attitude, which affects preferences and priorities toward learning something new ${ }^{25}$. Attitudes toward computers have been assessed in several studies ${ }^{17,22}$ using the Attitudes Toward Computers Questionnaire (ATCQ), a tool developed in 1992 by Jay \& Willis ${ }^{26}$. The ATCQ is a 35item multidimensional scale that has been used to assesses seven dimensions of attitudes toward computers among varied age subjects.

In general, attitudes toward computers appear to be influenced by various factors, four of which are presented:

a) User-friendly programs: examples of these include a study by Goodman \& Blake, who designed a self-paced and easy-to-use computer-based nutrition education 
program for African American adults. They suggested that a computer program must be interactive, user-friendly, and engaging to its targeted population ${ }^{27}$.

Probst et al., evaluated perceptions of diabetic older adults toward the use of a self-administered diet history program. Their results indicated that computer programs for older adults should ensure simplicity in their design ${ }^{28}$. Czaja et al.also reported that simplicity of design when working with older adults allows them to perform tasks easily without getting frustrated, therefore fostering a positive attitude toward working with computers ${ }^{22}$.

b) Training: Segrist et al. evaluated how training promoted changes in attitudes toward computers in a small group of adults aged 47-86 years who attended introductory computer courses. To measure the participants' attitudes, they administered the Jay \& Willis ATCQ ${ }^{26}$, and concluded that computer attitudes are modifiable, and that personalized computer training is effective for change ${ }^{17}$. Demiris et al. evaluated the perceptions and expectations of seniors in regard to different types of technology installed in their homes. They reported that older adults had positive attitudes toward technology and were far from being technophobic, even though they needed to learn the skills to use technology ${ }^{29}$.

Another example that illustrates the importance of training as a factor that influences attitudes toward technology, is a study by Dauz et al. of older patients recently diagnosed with obstructive sleep apnea (OSA). In that study, patients were trained to use the main functions of a computer to access a website that would provide general education about their disease. Therefore, computers were installed in patients' homes and training was provided, including written materials to follow. The authors concluded that computer training was effective for older adults to learn to use the Internet and to improve their health education knowledge, skills and/or adherence to treatment ${ }^{30}$. Wallen et al. also reported that computer-based methods can be an effective training tool for older adults to learn health information, since computer-based training designs, based on cognitive theories, may support higher levels of learning more than commonly used designs ${ }^{9}$.

c) Age: literature regarding the influence of age on attitude toward technology is controversial because of its close interrelationship with computer experience. However, 
some authors report that older adults are more likely to have negative attitudes toward computers than their younger peers ${ }^{22}$.

d) Experience with computers: Czaja et al. evaluated whether attitudes toward computers were influenced by direct computer experience, and concluded that experience with computers resulted in more positive attitudes when compared to age and gender ${ }^{22}$. A positive initial experience with computers is a key factor for older adults to learn about computers and reduce technological alienation ${ }^{25,26}$. Computer experience is also related to training, and the type and difficulty of the task that has been performed. It can be influenced either positively or negatively by the amount of training that a person has received $^{17,22}$.

All of the factors mentioned above influence attitudes and, therefore, are associated with preferences toward use of technology ${ }^{22}$. In addition to understanding the factors that may influence attitudes, it is also important to understand those related to adoption of technology. Since attitudes tend to guide behavior, it is common to find factors influencing both attitudes toward and adoption of technology ${ }^{4}$.

\section{Adoption of technology}

Adoption of technology involves motivation and ability ${ }^{31}$. Older adults need to be motivated, have proper skills and cognitive ability to learn new technology and to understand how its adoption will provide benefits, such as improving their quality of life and being cost-effective ${ }^{2}$. Five factors that may encourage older adults to adopt technology include:

1. Perceived need: If older adults do not perceive the usefulness and benefit of technology, they will not be motivated to adopt it ${ }^{4,25}$.

2. Cognitive and functional ability: Cognitive ability plays an important role in the adoption of technology because it is required for new learning, while functionality allows the use of computer components ${ }^{4}$.

3. Cost: Older adults' choices tend to be cost-benefit driven, therefore, before making an investment in technology, they analyze the benefits they will obtain from it ${ }^{25}$. Especially for those among the lower income brackets ${ }^{31}$, cost may be seen as a barrier to adopt technology. 
4. Skills: Without the appropriate skills, older adults will be reluctant to adopt new technology 31 .

5. Ease of use: This is a primary driver of consumer intentions to adopt technology 32 .

Other factors that influence adoption of technology include age, gender and education, attitudes toward technology and access to technology also influence the adoption of technology ${ }^{4}$.

\section{Barriers to use of technology}

As people age, cognitive and functional capacities decline ${ }^{4,12}$. Mynatt et al. reported that it is important to assess physical decline and memory capabilities when designing technology for older adults, so that technology does not become a potential barrier for this population ${ }^{12}$.

In general, authors are concerned about ethical and privacy issues that can arise from the use of technology and that, although ubiquitous to the entire population, appear to be increased among older adults ${ }^{2}$. Misinterpretation of information and/or instructions, fraud and vulnerability when using online services, and lack of economic resources, are other examples of barriers or limitations for older adult's use of technology ${ }^{18,23,30,33}$. Moreover, lack of broadband Internet access has also been reported as a frequent barrier for older adult's use of technology, especially computers. In addition, availability of technology does not always mean accessibility and usage of it, and this can also be considered as a barrier ${ }^{2}$.

Some older adults also question usefulness, reliability and benefit of the costs of technology ${ }^{29,31}$. Costs can be seen as expensive for persons on fixed incomes ${ }^{7,34}$, and this may make technology less accessible to older adults among the lower income brackets. However, as the population continues to age, it will become both socially and economically effective to support the independence of older adults by using technology ${ }^{4}$. 


\section{Education and technology}

\section{The Benefits}

Computers have become an important resource for promotion of health and nutrition education ${ }^{10,30}$. Computer-based programs can engage older adults with limited literacy by providing interactivity through the use of audio and graphics to limit the amount of reading required ${ }^{27}$. Educational literature suggests that older adults prefer getting smaller amounts of information at a time, with short and clear messages ${ }^{37}$. This can also be applied to the preparation of technology-based educational materials.

By using technology, older adults can have better control of what they learn because they may select the topic, sequence, duration, and often the pace of a presentation ${ }^{36}$. Furthermore, the use of touch-screen technology and CD-ROMS for presentations require no previous familiarity with computers, minimize literacy barriers, and are able to meet older adults' needs and preferences ${ }^{9,27}$. Other authors have also reported positive results from the use of technological devices to improve general health issues, such as adherence to medication, home safety, and improvement of low vision among older adults ${ }^{24,35,36}$.

\section{Importance of design and development}

Although technology is being increasingly used for a wide variety of tasks, it is not usually developed by older adults nor targeted at their age group ${ }^{7}$. According to Coughlin, older adults should be considered by technology researchers, policymakers, marketing groups and corporations when developing new ideas for this population ${ }^{33}$.

Technology and aging have a "reciprocal influence" on one another. This means that the way people age will affect how technology is designed for older adults. At the same time, technology will impact the aging process, improving it and allowing for a better quality of life ${ }^{7}$. Therefore, consideration of older adult's characteristics, psychological and physical needs, preferences and cognitive skills, should inspire the development and design of technology for this age group. This will also influence adoption and positive attitudes of older adults toward using technology 11,22, 24 . 


\section{Topics and formats of preference}

Although some of the literature cited about preferences refers to non-computerbased educational materials, it is still important to consider these when evaluating technological education. The opinions of older adults about topics, formats of most interest and preferences, can be applied to either computer-based or traditional education. Unfamiliar formats and/or techniques for learning may influence negatively or deter their use of technology. For older adults, font size, color, graphics and content are especially relevant 31,40

Older adults are interested in a wide variety of health and nutrition topics ${ }^{38}$. Krinke revealed that they appear mostly interested in nutrient retention in food preparation, and in getting their money's worth in buying foods ${ }^{38}$. Other authors ${ }^{39,37}$ also suggest food safety and food handling behaviors as topics of interest for older adults, as well as diet related topics such as salt intake, weight control and nutritional adequacy of the diet among others.

Literacy levels should also be considered when developing educational programs for older adults ${ }^{42}$. According to the 2003 National Assessment of Adult Literacy (NAAL), adults age $65+$ represented only $15 \%$ of the NAAL population, but $26 \%$ of the lowest prose literacy level ${ }^{41}$. Macario et al. revealed that the best nutrition education strategies for low literacy older adults were those that enhanced nutritional knowledge but only required minimal literacy, such as food models, games, etc ${ }^{42}$.

Many subjects, according to their literacy level, preferred using audiotapes instead of printed materials ${ }^{42,44}$. Individuals with higher literacy levels also preferred simply written materials. In general, it has been reported that older adults prefer print materials such as newspapers and magazines to obtain nutrition information; they can re-read them at their own pace, and keep the information for future reference ${ }^{37,43}$. 


\section{Purpose}

Given the importance of technology use and its application to many daily activities that older adults perform, the purpose of this study was to determine the preferences that older adults have toward the use of technology to learn about nutrition and health.

Therefore, the main research objectives that will be addressed in this study are: a) older adults' demographic and self-rated health characteristics; b) current use of computers and technology; c) factors that motivate and/or influence attitudes and interest toward technology; and d) preferred formats and topics of interest for nutrition and/or health education. 


\section{References}

1. Pew Internet and American Life Project. Demographics of Internet Users. Available at: http://207.21.232.103/trends/User_Demo_1.11.07.htm. Accessed 03-08-2007.

2. Morgan REJ. Technology greets the age wave. The Gerontologist. 2005;45:704-710.

3. Microsoft Corporation. Shifting Workplace Demographics and Delayed Retirement. Available at: http://www.microsoft.com/enable/aging/demographics.aspx. Accessed 08-04-2006.

4. Czaja SJ, Fisk AD, Rogers WA, Charness N, Nair SN, Sharit J. Factors predicting the use of technology: Findings from the center for research and education on aging and technology enhancement (CREATE). Psychology and Aging. 2006;21:333-352.

5. Lansley P. Extending quality life (EQUAL): New horizons for ageing research. Quality in Ageing. 2006;7:6-14.

6. Pinto MR, De Medici S, Zlotnicki A, Bianchi A, Van Sant C, Napoli C. Reduced visual acuity in elderly people: The role of ergonomics and gerontology. Age and Aging. 1997;26:339-344.

7. Cutler SJ. Ageism and technology. Generations. 2005;29:67-72.

8. Painter J, North J. Using web-based computer nutrition education to effect attitude toward soy products in an elderly population. The Journal of Nutrition. 2004;134:1248S$1293 \mathrm{~S}$.

9. Wallen ES, Mulloy KB. Computer-based safety training: An investigation of methods. Occupational Environmental Medicine. 2005;62:257-262.

10. Flanagan N, Waltz-Hill M, Lewis NM, Eskridge K. Computer-assisted nutrition education. Journal of the American Dietetic Association. 2002;102:1751. 
11. Metz D. Innovation to prevent dependency in old age. British Medical Journal. 2000;320:460-461.

12. Mynatt ED, Melenhorst AS, Fisk, A.D. and Rogers, W.A. Aware technologies for aging in place: Understanding user needs and attitudes. Pervasive Computing. 2004;3:36-41.

13. Pevzner BA, Kaufman DR, Hilliman C, et al. Developing computer skills and competencies in seniors. American Medical Informatics Asociation. 2005;1078.

14. Abeles N, Cooley S, Deitch IM, et al. Why practitioners need information about working with older adults. American Psychological Association. Available at: http://www.apa.org/pi/aging/practitioners/why.html. Accessed 07-24-2006.

15. U.S. Census Bureau Current Population Reports. 65+ in the United States. 2005:23209.

16. Center for Disease Control (CDC). The State of Aging and Health in America. Available at: www.cdc.gov/aging/pdf/saha_exec_summary_2007.pdf. Accessed 04-032007.

17. Segrist K. Attitudes of older adults toward a computer training program. Educational Gerontology. 2004;30:563-571.

18. Fox S. Pew Internet: Older Americans and the Internet - Report. Available at: http://207.21.232.103/PPF/r/117/report_display.asp. Accessed 8-31-2006.

19. SeniorNet. SeniorNet survey on Internet use. Available at: http://www.seniornet.org/php/default.php. Accessed 12-07-2006.

20. Fox S. Pew Internet \& American Life Project Presentation: The Future of the Internet as Baby Boomers Age. Available at: http://207.21.232.103/PPF/r/48/presentation_display.asp. Accessed 08-31-2006. 
21. Molinari DL, Blad P, Martinez M. Seniors' learning preferences, healthy self-care practices and computerized education implications. Online Journal of Rural Nursing and Health Care [serial online]. Accessed 12-27-2005.

22. Czaja SJ. Age differences in attitudes toward computers. The Journals of Gerontology. 1998;53B:329-340.

23. Lawhon T, Ennis D, Lawhon D. Senior adults and computers in the 1990's. Educational Gerontology. 1996;22:193-201.

24. Sterns AA. Curriculum design and program to train older adults to use personal digital assistants. The Gerontologist. 2005;45:828-834.

25. Melenhorst AS, Rogers WA. The use of communication technologies by older adults: Exploring the benefits from the user's perspective. Proceedings of the Human Factors and Ergonomics Society 45th Annual Meeting. 2001:221-225.

26. Jay GM, Willis SL. Influence of direct computer experience on older adults' attitudes toward computers. Journal of Gerontology. 1992;47:250-257.

27. Goodman J, Blake JA. Nutrition education: A computer-based education program. Journal of Health Care for the Poor and Undeserved. 2005;16:118-127.

28. Probst YC, Krnavek C, Lockyer L, Tapsell LC. Developing a self-administered computer assisted dietary assessment tool for use in primary healthcare practice: Perceptions of nutrition and computers in older adults with T2DM. Asia Pacific Journal of Clinical Nutrition. 2004;13.

29. Demiris G, Rantz MJ, Aud MA, et al. Older adults' attitudes towards and perceptions of smart home technologies: A pilot study. Medical Informatics. 2004;29:87-94.

30. Dauz E, Moore J, Smith CE, Puno F, Schaag H. Installing computers in older adults' homes and teaching them to access a patient education web site. CIN: Computers, Informatics, Nursing. 2004;22:266-272. 
31. Melenhorst AS, Bouwhuis DG, Rogers WA. Older adults' motivated choice for technological innovation: Evidence for benefit-driven selectivity. Psychology and Aging. 2006;21:190-195.

32. Brown SA, Massey AP, Montoya-Weiss MM, Burkman JR. Do I really have to? User acceptance of mandated technology. European Journal of Information Systems. 2002;11:283-295.

33. Coughlin J. Invention vs innovation: Technology and the future of aging. Aging Today. 2006;27:3.

34. McCreadie C, Stuchbury R. Who can afford computers? Working With Older People. 2006;10:15.

35. Horowitz A, Brennan M, Reinhardt JP, MacMillan T. The impact of assistive device use on disability and depression among older adults with age-related vision impairments. The Journals of Gerontology. 2006;61B:S274-S280.

36. Sweeney MA, Chiriboga DA. Evaluating the effectiveness of a multimedia program on home safety. The Gerontologist. 2003;43:325-334.

37. Chambers DH, Higgins MM, Roeger C, Allison AM. Nutrition education displays for young adults and older adults. Health Education. 2004;104:45-54.

38. Krinke UB. Nutrition information topic and format preferences of older adults. Journal of Nutrition Education. 1990;22:292-297.

39. Higgins MM, Clarke Barkley M. Concepts, theories and design components for nutrition education aimed at older adults. Journal of Nutrition for the Elderly. 2003a;23:57-75.

40. Wellman N, Rosenzweig LY, Lloyd JL. Thirty years of the older Americans nutrition program. Journal of the American Dietetic Association. 2002;102:348-350. 
41. Sayhoun NR. Nutrition education for the healthy elderly population: Isn't it time? Journal of Nutrition Education and Behavior. 2002;34:S42-S47.

42. Macario E, Emmons KM, Sorensen G, Hunt MK, Rudd RE. Factors influencing nutrition education for patients with low literacy skills. Journal of the American Dietetic Association. 1998;98:559-564.

43. Lancaster KJ, Smiciklas-Wright H, Ahern F, Achterberg C, Taylor-Davis S. Evaluation of a nutrition newsletter by older adults. Journal of Nutrition Education. 1997;29:145-151.

44. Higgins MM, Clarke Barkley M. Improving effectiveness of nutrition education resources for older adults. Journal of Nutrition for the Elderly. 2004;23:19-54. 
CHAPTER II

\section{OLDER ADULTS' PREFERENCES FOR TECHNOLOGICAL NUTRITION EDUCATION}




\begin{abstract}
The use of computer-based and personal assistive technology is projected to increase as the boomer generation continues to age. Technology is infiltrating and improving older adults' life, including their education. This study determined older adults' preferences toward the use of technology to learn about nutrition and health. The sample included 132 volunteer subjects, mostly female, white non-Hispanic, ranging in age from 65-92 years recruited from local organizations, senior centers, churches, and senior apartments. All participants completed a newly developed, 32-item pilot tested questionnaire that included demographic and self-rated health characteristics, current use of technology, factors that motivate and/or influence attitudes and interest toward use of technology, and preferred formats and topics of interest for nutrition and health education information. The results indicate that overall, older adults self-rated their health as either excellent or good, and that those in the younger group and among the higher income brackets and education levels were more likely to use computers than those that were older, with less income, and education levels . Findings also indicate that older adults were interested and willing to learn about technology, with positive attitudes toward it and a high demand for user-friendly programs and training. Finally, results show that although newsletters, magazines and TV were mostly preferred by older adults, computers were also considered very helpful and were used to learn about nutrition and health information.
\end{abstract}




\section{INTRODUCTION}

Computer-based technology continues to impact our society, becoming a major component of work, environments, education, entertainment and communication ${ }^{1}$. For older adults, technology also fosters social interaction, maintenance of autonomy, better functionality, comfort, and safety within homes ${ }^{2,3}$. Therefore, identifying older adults' preferences and expectations for using technology and learning new information is increasingly important.

Use of the Internet by men and women became equal in 2004, acknowledging the World Wide Web as an important health information source ${ }^{4}$. Currently, the percentage of Americans over 65 using the Internet was reported to be $33-34 \%{ }^{6}$, but by the year 2010 it is estimated that more than $70 \%$ of all older adults will be using the Internet ${ }^{7}$, since it is becoming increasingly cost-effective and socially important to support the independence of older adults ${ }^{1,8}$. Older adults are therefore starting to experience the benefits of online health searches, shopping, banking and email, which have increased among this group ${ }^{4,5}$.

It is generally believed that attitudes tend to guide behavior and may influence willingness to accept and use technology ${ }^{10}$. Older adults are reported to have a presentoriented attitude, affecting preferences and priorities toward learning something new ${ }^{9}$. Attitudes have been assessed in various studies, and appeared to be influenced not only by socio-demographic factors such as age, income and education, but also by factors such as having user-friendly programs, training, and experience with computers ${ }^{5,10-15}$. Data examining attitudes toward computers have shown that experience with computers resulted in more positive attitudes when compared to age and gender ${ }^{10}$, and that the nature of computer experience is what determines older adults' attitudes when compared to younger groups ${ }^{1}$.

Adoption of technology involves motivation and ability ${ }^{16}$, therefore playing an important role toward attitudes and preferences. Older adults need to be motivated to learn new skills, have cognitive ability to retain and perform them, and perceive the benefits that technology may provide, such as improvement of their quality of life and being cost-effective ${ }^{17}$. 
In addition to understanding factors that influence attitudes toward adoption and use of technology, it is also important to consider which formats and topics are of interest to older adults when learning about nutrition and/or health. This will help improve the development and design of computer-based programs for older adults, which in turn, will also influence their preferences toward technology.

In general, it has been reported that newspapers and magazines are mostly preferred by older adults to obtain nutrition information, so font size, color, graphics and content are especially relevant ${ }^{16,18-20}$. However, depending on their literacy level, many individuals prefer audiotapes instead of printed materials ${ }^{21,22}$.Computer-based programs have also become important resources for promotion of health and nutrition education ${ }^{11}$, 23 . For example, the use of touch-screen technology and CD-ROMS for presentations require no previous familiarity with computers, minimize potential literacy barriers, and are able to meet older adults' needs and preferences ${ }^{13,24}$.

Older adults are interested in a wide variety of health and nutrition topics ${ }^{25}$. The literature reveals that they are mostly interested in nutrient retention in food preparation, and in getting their money's worth in buying foods ${ }^{25}$. Data also suggest food safety and food handling behaviors, as well as diet related topics such as salt intake, weight control and nutritional adequacy of the diet as topics of interest for older adults ${ }^{18,26}$.

Studies reporting combined results from technology preferences for nutrition and health education in older adults are limited. Therefore, the purpose of this investigation was to add to the body of knowledge by determining older adults' preferences toward the use of technology, particularly with implications for learning about nutrition and/or health. 


\section{METHODS}

\section{Subject and site selection}

To meet inclusion criteria, subjects needed to be 65 years of age or older, community-based, and without diagnosed cognitive impairment. Volunteers were recruited via telephone or in-person at different sites within Manhattan, Kansas. One of the selected sites was beyond city limits (i.e: Junction City, Kansas). Permission was granted from coordinators or supervisors at the different sites to distribute and post flyers. Sites selected included senior centers, several local organizations, churches, and senior apartments. Some interviews were also conducted at individuals' homes at a mutually agreed upon time and date. The study was approved by the Institutional Review Board at Kansas State University, and written informed consent was obtained from each volunteer. No monetary compensation was given to anyone for participating.

\section{Sample Size}

A convenient sample of approximately 150 subjects was intended, however, only 132 subjects participated. This smaller number resulted because many questionnaires that had initially been provided for participants were either not completed or returned, or because subjects did not attend data collection sessions on the dates that had been announced. In addition, a total of 5 questionnaires were excluded because subjects were younger than the required 65 years of age.

\section{Data collection instrument}

\section{Questionnaire development}

A five page, single-sided questionnaire was developed to collect information from participants. The instrument included 32 questions divided into three sections. One addressed questions about computer usage, training, attitudes and interest towards computers; factors that influenced computer usage; and, preferred health education formats. A second section gathered demographic information, including gender, age, ethnicity, marital status, education, employment status, and range of income. The third 
section obtained information on self-rated health, concern toward select chronic diseases such as cancer, diabetes, hypertension and others, and overall satisfaction with life. Questions regarding nutrition topics of interest and use of technology to inquire about nutrition were also included.

\section{Administration of Questionnaire}

The study was described in small group settings or to individuals; subjects signed and dated the informed consent and then proceeded with answers to the questionnaire. The questionnaire had been pilot tested with two separate groups of individuals, and it became evident that conducting personalized interviews would not be time-effective in the group settings of five or more persons. Therefore, the questionnaire was modified (by eliminating interviewer prompts and clarifying wording) to be self-administered. However, a total of 7 questionnaires were read to people who had either forgotten their glasses or did not feel comfortable reading it by themselves. Completion of the questionnaire took between 10 to 15 minutes.

\section{Data analysis procedures}

All data analyses were performed using SPSS for Windows version 13.0 (SPSS, Inc., Chicago, IL) software. Descriptive analysis procedures were used ${ }^{27}$ with the demographic data and to describe frequencies of other variables, including computer use, training, and interest in technology among others. Chi-square non-parametric test for independence was used to determine relationships among the variables and for determining statistical significance ${ }^{28}$. All $\mathrm{P}$ values are two-tailed $(\alpha=0.05)$. 


\section{RESULTS}

\section{Characteristics of the study population}

A total of 132 participants comprise the study sample. However, response numbers vary, since not all subjects answered every question. Descriptive analysis of the demographic characteristics of the study population is presented in Table 1. The mean age of the entire group was $75 \pm 7$ years. The age variable was divided into two subgroups, the younger old (65-74 years), which accounted for $51.6 \%$ of the 128 subjects who responded, and the older old (75-94 years), which represented $48.4 \%$.

The mean number of years of education was $15 \pm 3$, and this variable was divided into three groups for statistical analyses: individuals with an education level equal to or less than high school, those with a college degree, and those with a graduate degree. A total of 84 individuals $(64.6 \%)$ had received either college or graduate education, while only 46 of the $130(35.4 \%)$ had high school or less education.

Of the 132 subjects, 83 were female. Most participants were either married or widowed (119), white, non-Hispanic (124) and retired (112). In addition, $47.9 \%$ of the participants reported an annual income of $\$ 40,000$ or greater.

\section{Health characteristics}

Table 2 shows the self-rated health characteristics of the study subjects. Of a total of 131 subjects, 108 rated their health as either "excellent" or "good", while only 5 $(3.8 \%)$ considered it to be "poor" when asked how they would rate their overall physical health. Similarly, 84 subjects (64.1\%) rated their eyesight as "good" and 22 (16.8\%) of them as "fair" when asked how they would describe their eyesight. In relation to their hearing however, the rating was slightly lower, since 64 subjects $(48.9 \%)$ reported that it was "good", and 37 (28.2\%) of them felt it was only "fair".

Health issues of concern are also presented in Table 2. High blood pressure was the single health issue that concerned most participants, followed by arthritis, heart disease and diabetes. Participants were also asked to compare their health now to how it was five years ago (results not shown in a table). Of 130 subjects, 88 (67.7\%) reported that it was about the same, $21(16.2 \%)$ said it was worse, and $16(12.3 \%)$ said it was now 
better. In addition, when asked how they described their overall satisfaction with life at this time, of 130 respondents, 122 (93.8\%) indicated that it was either excellent or good.

\section{Use of computers and technology in general}

Table 3 reflects the use of computers by gender, age and education. The results of this table show that, of a total of 130 subjects, $82(63.1 \%)$ identified themselves as computer users. Using non-parametric statistical analysis, no significant difference was found between computer use and gender $\left(X^{2}=2.355 ; p\right.$-value $\left.=0.125\right)$. A small statistically significant difference was found between computer use and both age groups $\left(X^{2}=4.501 ; p\right.$-value $\left.=0.034\right)$, showing a higher use of computers within the younger age group (Figure 1.).

Among those who said they were computer users (82), 84.3\% used computers daily, with $31 \%$ reporting formal training or instruction in either very little or some amounts (results not shown in a table). Other types of technology used are shown in Table 4. These include the use of cell phones (78\%), ATMs (48\%), video games (20.3\%), and palm pilots $(6.5 \%)$. Familiarity with TV, VCRs, CDs and DVDs was very high and is also shown in Table 4.

Factors that influenced computer usage among the participants are shown in Table 5. Lack of time and convenience were most common. Easy access to computers, where they live, and lack of availability of computers were additional factors. Economic issues did not seem to influence participants (92.7\%); most of them did not have limited incomes. An additional question regarding factors that would encourage participants to use a computer and/or use it more often was asked (results not in a table). The two most common factors that would encourage subjects to use a computer or use it more often were: having simple to understand programs (51.6\%), and receiving instruction or training (37.3\%), followed by having access to a computer which is free of cost (23.8\%). The rest of the individuals were simply not interested.

From an open-ended question, more than half of the subjects reported that they were hindered to use technology. The main reasons included lack of time, lack of knowledge and/or computer training, age, and/or health impairments. Other factors mentioned by the participants included: difficulty to learn and understand specific 
computer jargon, cost, not owning a computer, lack of Internet access and/or lack of interest.

\section{Attitudes and interest toward technology}

Of a total of 129 subjects, $74(57.4 \%)$ felt that overall, technology was very helpful, although $28(21.7 \%)$ thought it was a little difficult to use. Only $12(9.3 \%)$ of the subjects indicated that technology was overwhelming (Figure 2.). Almost half of the entire group reported that they were at least a little interested in technology, with only 6 $(4.6 \%)$ indicating that they were not interested at all (Figure 3.). In addition, of those 64 individuals who had little interest toward technology, $60.7 \%$ would be more encouraged to use it if they had programs that were simple to understand (results not shown in a table), and if they received instruction or training (41\%). Computer training among the participants is shown in Figure 4.

Willingness to use technology was also evaluated (Figure 5.), with 47 (36.4\%) of 129 participants reporting that they wanted to learn immediately, opposed to $32(24.8 \%)$, who said they would like to learn but not right now.

\section{Preferred formats and topics of interest for health education}

Newsletters, TV, and magazines were preferred by more than half of the entire group to learn about health (Table 6). Computers and the Internet were preferred by $45 \%$ of the subjects. Most participants however, reported that they regularly obtained their health information from the physician's office $(68.2 \%)$, magazines $(51.5 \%)$, and the TV $(45.5 \%)$. Only $36.4 \%$ of the subjects reported that they used computers to obtain health information (Table 7)

Because the focus of administering this questionnaire was to evaluate technology use to learn about nutrition and health, a few questions relating these topics were included. Participants were asked if there were any nutrition topics or issues of particular interest to them; the total number who expressed interest in a nutrition topic was 84 . As displayed in Table 8, participants who were interested in a certain topic were generally women $(61.9 \%)$ in both age groups, with college education, reported good overall physical health, married, retired and among the higher income brackets. An open-ended 
question revealed which nutrition topics were of interest, and are shown in Figure 6. The five most common ones were: hypertension, different types of diets, diabetes, recipes and healthy eating.

Participants were also asked whether they had ever used the computer to look up information on any of the listed nutrition topics of interest. Of 131 participants, one subject did not answer the question, and only 52 (39.7\%) said they used the computer to look up nutrition information. Table 9 characterizes the profile of those that used the computer to look up nutrition information; women (57.7\%), in the younger age group $(63.5 \%)$, and among the highest educated (44.2\% had graduate degrees). 


\section{DISCUSSION}

The purpose of this study was to determine preferences of older adults toward the use of technology for nutrition and/or health education. Main objectives of the study that are presented here are: a) older adults' current use of computers and technology; b) factors that motivate and/or influence attitudes and interest toward technology; and lastly, c) preferred formats and topics of interest for nutrition and/or health education.

Current use of computers and technology-Overall, the findings indicated that computers and technology in general were widely used by participants. No statistically significant differences in computer use by gender were found. However, by age, the younger group (65-74) had higher use of computers than the older group (75+ years), with a slight statistically significant difference shown. This difference however, may have been due to chance and/or the fact that the sample size was small. These results parallel those of other studies and reports ${ }^{1,6,29}$, indicating that among further age cohorts older adults use less technology.

In consonant with the literature, the descriptive data indicated that income and education played a significant role in adoption and use of technology. Although attempts were made to secure a diverse group of older adults within the Manhattan, Kansas community, volunteers were mostly retired, well-educated, and among the higher income brackets. These results, therefore, may not be generalized to other groups of older adults. Moreover, participants reported having received very little computer training. This is consistent with results obtained by others who reported that in general, older adults need to receive more training to adopt and use technology ${ }^{11,17}$. Furthermore, the data showed that lack of training, knowledge and computer jargon were some of the reasons that hindered use of technology.

Factors that motivate and/or influence attitudes and interest toward technology Although this study considered attitudes to be an important component of computer use and adoption, the Attitudes Toward Computers Questionnaire developed by Jay \& Willis ${ }^{14}$ was not used. Other dimensions included in that instrument (eg., comfort, efficacy, control, and dehumanization) were not pertinent to this study. Therefore, a questionnaire was developed specifically for this study to obtain data needed to achieve study goals. 
The results of this study also highlight the importance of assessing attitudes and interest of older adults' in technology to determine their preferences toward its use. Older adults generally had positive attitudes toward technology, and described it as being very helpful. Participants were interested and willing to learn about technology. Data also indicated that user-friendly programs and training would encourage them to use technology more often.

These results are consistent with reports by others ${ }^{2,10,12,16,30,31}$, and suggest that special attention should be given to training and having easy-to-use programs that will improve attitudes and interest toward the use of technology. Because attitudes are also influenced by computer experience ${ }^{30}$, it is important to note that $63.1 \%$ of the sample were computer users, thus were expected to have broad experience with computers.

Preferred formats and topics of interest for nutrition and/or health education Finally, the data indicated that older adults were interested in nutrition and/or health, and that the topics of most interest were diets, diabetes, healthy eating, and food preparation (recipes). These results support the findings encountered several years ago by Krinke ${ }^{25}$ and Higgins ${ }^{26}$, who found that older adults were interested in the impact of nutrition on health and food preparation. In addition, the present study showed that preferred formats for health education among older adults were magazines, newsletters and TV. This was also shown by Macario et al. in 2004 when they reported that individuals, despite their education and literacy level, continued to prefer written materials as sources of health information ${ }^{22}$. Other authors have also reported similar findings ${ }^{19,25}$.

Limitations - The two major limitations of this study were the small sample size and a lack of diversity among the study population. A larger sample size would have increased statistical power; a more diverse population would have allowed further analysis of results, and extrapolation to other older adult groups. Although an effort to secure a diverse population was made (for example in income, education and computer use) by contacting local senior centers and community apartments for older adults, the number of volunteers from those sites was somewhat limited, even after follow-up visits. A third limitation of the present study included lack of time to further test the questionnaire prior to implementation. As indicated, the data collection instrument was modified to allow self-administration, but not all questions were answered, thus 
interpretation of some questions was limited, raising some question about validity of responses.

Even with those limitations, there were positive outcomes from this study. It does represent the older adult population of Manhattan, with many retirees and/or ex-faculty members of Kansas State University. Although further research on development of computer-based nutrition education programs for older adults in Kansas is needed, this study provides a basis for determining preferred formats of delivery of nutrition and health information in this age group.

The overall outcome of this study supported the literature describing that older adults' use and adoption of technology as well as their attitudes toward it, are influenced by a variety of factors. These findings also demonstrate that older adults are interested and willing to learn technology to enhance their nutritional and/or health education. However, this interest can be sustained through user-friendly designs, and adequate training. 


\section{REFERENCES}

1. Czaja SJ, Fisk AD, Rogers WA, Charness N, Nair SN, Sharit J. Factors predicting the use of technology: Findings from the center for research and education on aging and technology enhancement (CREATE). Psychology and Aging. 2006;21:333-352.

2. Lansley P. Extending quality life (EQUAL): New horizons for ageing research. Quality in Ageing. 2006;7:6-14.

3. Pinto MR, De Medici S, Zlotnicki A, bianchi A, Van Sant C, Napoli C. Reduced visual acuity in elderly people: The role of ergonomics and gerontology. Age and Aging. 1997;26:339-344.

4. Fox S. Pew Internet: Older Americans and the Internet -- Report. Available at: http://207.21.232.103/PPF/r/117/report_display.asp. Accessed 8-31-2006.

5. Segrist K. Attitudes of older adults toward a computer training program. Educational Gerontology. 2004;30:563-571.

6. Pew Internet and American Life Project. Demographics of Internet Users. Available at: http://207.21.232.103/trends/User_Demo_1.11.07.htm. Accessed 03-08-2007.

7. Fox S. Pew Internet \& American Life Project Presentation: The Future of the Internet as Baby Boomers Age. Available at:

http://207.21.232.103/PPF/r/48/presentation_display.asp. Accessed 08-31-2006.

8. Molinari DL, Blad P, Martinez M. Seniors' learning preferences, healthy self-care practices and computerized education implications. Online Journal of Rural Nursing and Health Care [serial online]. Accessed 12-27-2005.

9. Melenhorst AS, Rogers WA. Proceedings of the human factors and ergonomics society 45 th annual meeting.

the use of communication technologies by older adults: Exploring the benefits from the user's perspective. 2001:221-225. 
10. Czaja SJ. Age differences in attitudes toward computers. The Journals of Gerontology. 1998;53B:329.

11. Dauz E, Moore J, Smith CE, Puno F, Schaag H. Installing computers in older adults' homes and teaching them to access a patient education web site. CIN: Computers, Informatics, Nursing. 2004;22:266-272.

12. Demiris G, Rantz MJ, Aud MA, et al. Older adults' attitudes towards and perceptions of smart home technologies: A pilot study. Medical Informatics. 2004;29:87-94.

13. Goodman J, Blake JA. Nutrition education: A computer-based education program. Journal of Health Care for the Poor and Undeserved. 2005;16:118-127.

14. Jay GM, Willis SL. Influence of direct computer experience on older adults' attitudes toward computers. Journal of Gerontology. 1992;47:250-257.

15. Probst YC, Krnavek C, Lockyer L, Tapsell LC. Developing a self-administered computer assisted dietary assessment tool for use in primary healthcare practice: Perceptions of nutrition and computers in older adults with T2DM. Asia Pacific Journal of Clinical Nutrition. 2004;13.

16. Melenhorst AS, Bouwhuis DG, Rogers WA. Older adults' motivated choice for technological innovation: Evidence for benefit-driven selectivity. Psychology and Aging. 2006;21:190-195.

17. Morgan REJ. Technology greets the age wave. The Gerontologist. 2005;45:704-710.

18. Chambers DH, Higgins MM, Roeger C, Allison AM. Nutrition education displays for young adults and older adults. Health Education. 2004;104:45-54.

19. Lancaster KJ, Smiciklas-Wright H, Ahern F, Achterberg C, Taylor-Davis S. Evaluation of a nutrition newsletter by older adults. Journal of Nutrition Education. 1997;29:145-151. 
20. Wellman N, Rosenzweig LY, Lloyd JL. Thirty years of the older americans nutrition program. Journal of the American Dietetic Association. 2002;102:348-350.

21. Higgins MM, Clarke Barkley M. Improving effectiveness of nutrition education resources for older adults. Journal of Nutrition for the Elderly. 2004;23:19-54.

22. Macario E, Emmons KM, Sorensen G, Hunt MK, Rudd RE. Factors influencing nutrition education for patients with low literacy skills Journal of the American Dietetic Association. 1998;98:559-564.

23. Flanagan N, Waltz-Hill M, Lewis NM, Eskridge K. Computer-assisted nutrition education. JADA. 2002;102:1751.

24. Wallen ES, Mulloy KB. Computer based safety training: An investigation of methods. Occupational Environmental Medicine. 2005;62:257-262.

25. Krinke UB. Nutrition information topic and format preferences of older adults. Journal of Nutrition Education. 1990;22:292-297.

26. Higgins MM, Clarke Barkley M. Concepts, theories and design components for nutrition education aimed at older adults. Journal of Nutrition for the Elderly. 2003a;23:57-75.

27. Morgan GA, Leech NL, Gloecker GW, Barrett KC. SPSS for Introductory Statistics. ; 2004.

28. Downie NM, Heath RW. Basic Statistical Methods. 4th ed. Harper \& Row; 1974.

29. Jamieson BA, Rogers WA. Age-related effects of blocked and random practice schedules on learning a new technology. The Journals of Gerontology. 2000;55B:P343P353.

30. Czaja SJ. Technological change and the older worker. In: Birren, James E. Schaie, K.Warner, ed. Handbook of the Psychology of Aging. 5th ed. San Diego, Calif: Academic Press; 2001. 
31. Mynatt ED, Melenhorst AS, Fisk, A.D. and Rogers, W.A. Aware technologies for aging in place: Understanding user needs and attitudes. Pervasive Computing. 2004;3:3641. 
Table 1. Demographic characteristics of the study population

$(n=132)$

Categorical variables

No.

$\%$

Age $(\mathrm{n}=128)$

65-74

75-94

66

51.6

$62 \quad 48.4$

Gender $(\mathrm{n}=132)$

Male

49

37.1

Female

83

62.9

Education $(\mathrm{n}=130)$

$\leq$ High school

46

35.4

College degree

42

32.3

Graduate degree

42

32.3

Income $(\mathrm{n}=119)$

$\geq \$ 40,000$

57

47.9

$\$ 30,000-\$ 40,000$

15

12.6

$\$ 20,000-\$ 30,000$

18

15.1

$\$ 10,000-\$ 20,000$

14

11.8

$\$ 5,000-\$ 10,000$

11

9.2

$<\$ 5,000$

4

3.4

Marital status ( $\mathrm{n}=131)$

Single

Married

4

3.1

Widowed

76

58.0

43

32.8

Divorced

Separated

7

5.3

1

0.0

Ethnicity (n=132)

White, Non-Hispanic

Hispanic

124

93.9

Black

4

3

3.0

Asian

1

2.3

0.8

\begin{tabular}{lcccc} 
Interval variables & Mean & SD & Median & Range \\
\hline & & & & \\
Age (yrs) & 74.7 & 6.7 & 74.0 & $65-94$ \\
Education (yrs) & 15.0 & 3.4 & 15.5 & $4-24$ \\
\hline
\end{tabular}




\section{Table 2. Self-rated health characteristics of the study population}

$(\mathbf{n}=131)$

\begin{tabular}{|c|c|c|}
\hline & No. & $\%$ \\
\hline \multicolumn{3}{|c|}{ Self-rated physical health } \\
\hline Excellent & 34 & 26.0 \\
\hline Good & 74 & 56.5 \\
\hline Fair & 18 & 13.7 \\
\hline Poor & 5 & 3.8 \\
\hline \multicolumn{3}{|l|}{ Eyesight } \\
\hline Excellent & 21 & 16.0 \\
\hline Good & 84 & 64.1 \\
\hline Fair & 22 & 16.8 \\
\hline Poor & 4 & 3.1 \\
\hline \multicolumn{3}{|l|}{ Hearing } \\
\hline Excellent & 24 & 18.3 \\
\hline Good & 64 & 48.9 \\
\hline Fair & 37 & 28.2 \\
\hline Poor & 6 & 4.6 \\
\hline \multicolumn{3}{|c|}{$*$ Health issues of concern $(n=129)$} \\
\hline High blood pressure & 64 & 49.6 \\
\hline Arthritis & 50 & 38.8 \\
\hline Heart disease & 39 & 30.2 \\
\hline Diabetes & 31 & 24.0 \\
\hline Cancer & 27 & 20.9 \\
\hline None & 20 & 15.5 \\
\hline Cataracts & 18 & 14.0 \\
\hline Macular degeneration & 9 & 7.0 \\
\hline Kidney disease & 4 & 3.1 \\
\hline Liver disease & 1 & 0.8 \\
\hline
\end{tabular}

* More than one category could be selected 
Table 3. Computer usage by gender, age group and educational level

\begin{tabular}{|c|c|c|c|c|c|c|}
\hline \multirow[b]{2}{*}{ Characteristics } & \multicolumn{2}{|c|}{ Computer users } & \multicolumn{4}{|c|}{ Non-computer } \\
\hline & No. & $\%$ & No. & $\%$ & $X^{2}$ & p-value \\
\hline \multicolumn{7}{|l|}{$\begin{array}{l}\text { Gender } \\
(n=130)\end{array}$} \\
\hline Male & 35 & 71.4 & 14 & 28.6 & 2.355 & 0.125 \\
\hline Female & 47 & 58.0 & 34 & 42.0 & & \\
\hline \multicolumn{7}{|l|}{$\begin{array}{l}\text { Age group } \\
(\mathrm{n}=126)\end{array}$} \\
\hline $65-74$ & 47 & 72.3 & 18 & 27.7 & 4.501 & 0.034 \\
\hline $75-94$ & 33 & 54.1 & 28 & 45.9 & & \\
\hline \multicolumn{7}{|l|}{$\begin{array}{l}\text { Education } \\
(\mathrm{n}=128)\end{array}$} \\
\hline$\leq$ High school & 17 & 38.6 & 27 & 61.4 & 18.780 & $<0.000$ \\
\hline College degree & 28 & 66.7 & 14 & 33.3 & & \\
\hline Graduate degree & 35 & 83.3 & 7 & 16.7 & & \\
\hline
\end{tabular}


Table 4. Types of technology familiar and/or used by participants

\begin{tabular}{lll} 
& No.* & $\%$ \\
\hline (n=131) & & \\
TV & 128 & 97.7 \\
VCR & 107 & 81.7 \\
CD/DVD & 94 & 71.8 \\
Specific computer programs & 54 & 41.2 \\
Touch screen & 31 & 23.7 \\
Others & 9 & 6.9 \\
& & \\
(n=123) & & 78.0 \\
Cell phone & 96 & 48.0 \\
ATM & 59 & 20.3 \\
Video game & 25 & 6.5 \\
Palm pilot & 8 & \\
\end{tabular}

* More than one category could be selected

Table 5. Factors that influence participant's computer usage $(n=124)$

\begin{tabular}{llc} 
Factor & No.* & $\%$ \\
\hline & 39 & 31.5 \\
Lack of time & 31 & 25.0 \\
Convenience & 21 & 16.9 \\
Easy access & 19 & 15.0 \\
Others & 11 & 8.9 \\
Where I live & 9 & 7.3 \\
Lack of availability of computers & 9 & 7.3 \\
Economic issues &
\end{tabular}

* More than one category may have been selected 
Table 6. Preferred formats to learn about health education

\begin{tabular}{lcc}
$(\mathbf{n}=\mathbf{1 3 2})$ & & \\
Formats & No.* & $\%$ \\
\hline & 74 & 56.1 \\
Newsletters & 69 & 53.5 \\
TV & 66 & 50.0 \\
Magazines & 58 & 45.0 \\
Computers/Internet & 54 & 40.9 \\
Personal interaction & 52 & 39.4 \\
Newspapers & 51 & 38.6 \\
Brochures & 34 & 25.8 \\
Books & 19 & 14.7 \\
Radio & &
\end{tabular}

* More than one category could be selected

Table 7. Most used formats to learn about health education $(n=132)$

\begin{tabular}{lll} 
Formats & No.* & $\%$ \\
\hline & 90 & \\
Physician's office & 68 & 68.2 \\
Magazines & 60 & 51.5 \\
TV & 53 & 45.5 \\
Newspapers & 50 & 40.2 \\
Friends/relatives & 48 & 37.9 \\
Computers/Internet & 33 & 36.4 \\
Dietitian & 25 & 25.0 \\
Radio & 22 & 18.9 \\
Dentist's office & & 16.7 \\
\hline
\end{tabular}

* More than one category could be selected 
Table 8. Profile of participants who were interested in a nutrition topic $(n=84)$

\begin{tabular}{|c|c|c|}
\hline Variable & No. & $\%$ \\
\hline \multicolumn{3}{|l|}{ Gender } \\
\hline Male & 32 & 38.1 \\
\hline Female & 52 & 61.9 \\
\hline \multicolumn{3}{|l|}{ Age } \\
\hline $65-74$ & 41 & 49.4 \\
\hline $75-94$ & 42 & 50.6 \\
\hline \multicolumn{3}{|l|}{ Education } \\
\hline$\leq$ High School & 24 & 28.6 \\
\hline College degree & 32 & 38.1 \\
\hline Graduate degree & 28 & 33.3 \\
\hline \multicolumn{3}{|l|}{ Marital status } \\
\hline Single & 3 & 3.6 \\
\hline Married & 50 & 59.5 \\
\hline Widowed & 26 & 31.0 \\
\hline Divorced & 4 & 4.8 \\
\hline Separated & 1 & 1.2 \\
\hline \multicolumn{3}{|l|}{ Retired } \\
\hline Yes & 67 & 79.8 \\
\hline No & 17 & 20.2 \\
\hline \multicolumn{3}{|l|}{ Persons in household } \\
\hline One & 32 & 38.1 \\
\hline Two & 49 & 58.3 \\
\hline Three & 3 & 3.6 \\
\hline \multicolumn{3}{|c|}{ Self-rated physical health } \\
\hline Excellent & 25 & 30.1 \\
\hline Good & 48 & 57.8 \\
\hline Fair & 7 & 8.4 \\
\hline Poor & 3 & 3.6 \\
\hline \multicolumn{3}{|l|}{ Income } \\
\hline$\geq \$ 40,000$ & 39 & 49.4 \\
\hline$\$ 30,000-\$ 40,000$ & 11 & 13.9 \\
\hline$\$ 20,000-\$ 30,000$ & 12 & 15.2 \\
\hline$\$ 10,000-\$ 20,000$ & 10 & 21.5 \\
\hline$\$ 5,000-\$ 10,000$ & 6 & 8.9 \\
\hline$<\$ 5,000$ & 1 & 1.3 \\
\hline
\end{tabular}


Table 9. Profile of participants who used the computer to look up nutrition information

$(\mathbf{n}=52)$

Variable

Gender

Male

Female

Age

65-74

$75-94$

Education

$\leq$ High School

College degree

Graduate degree
No.

22

30

33

19

63.5

36.5

10

19

23

19.2

36.5

44.2

Self-rated physical health

Excellent

Good

Fair

Poor
11

36

2
21.6

70.6

3.9

3.9 
Figure 1. Computer usage by age and gender

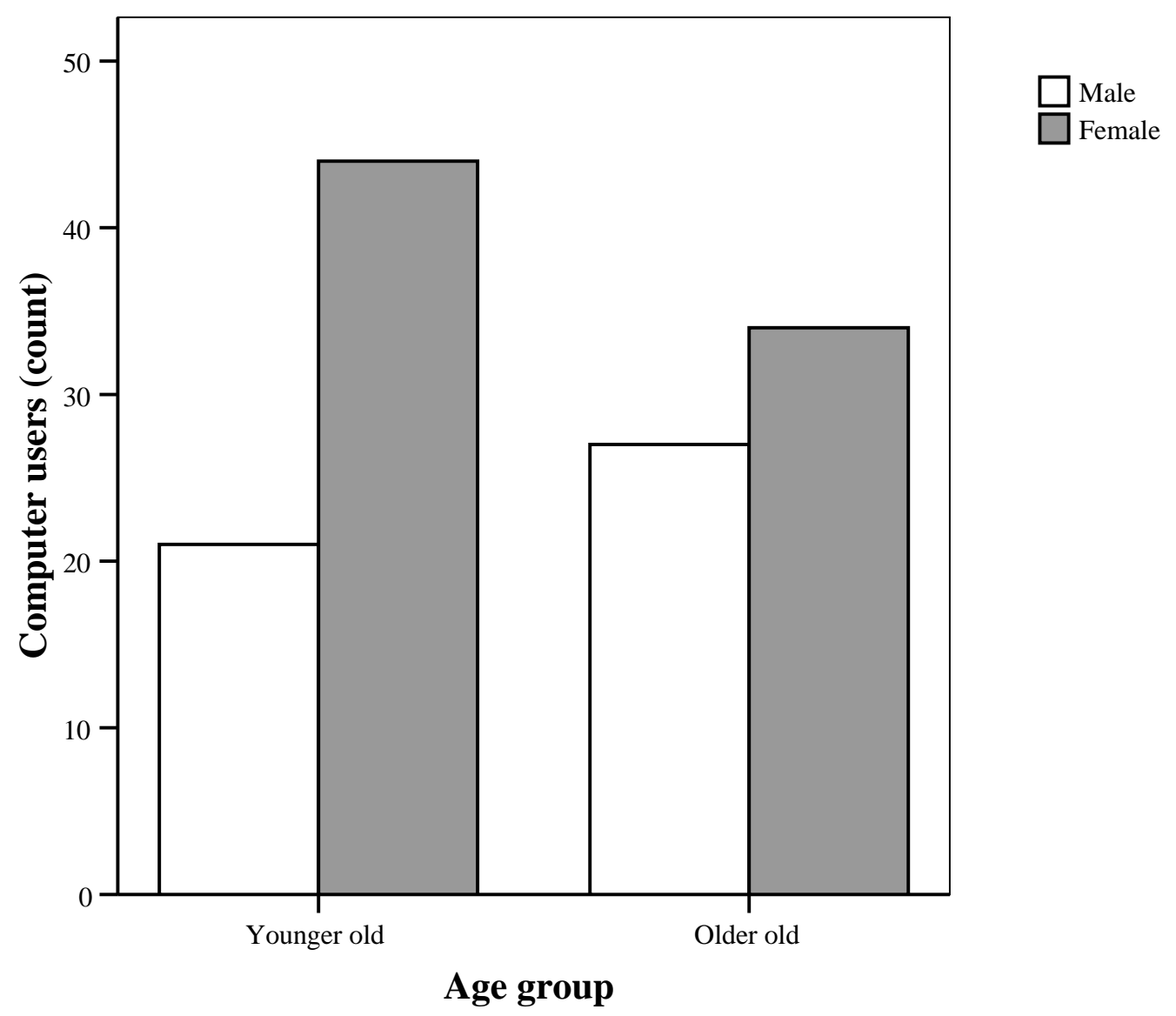


Figure 2. Opinion toward technology

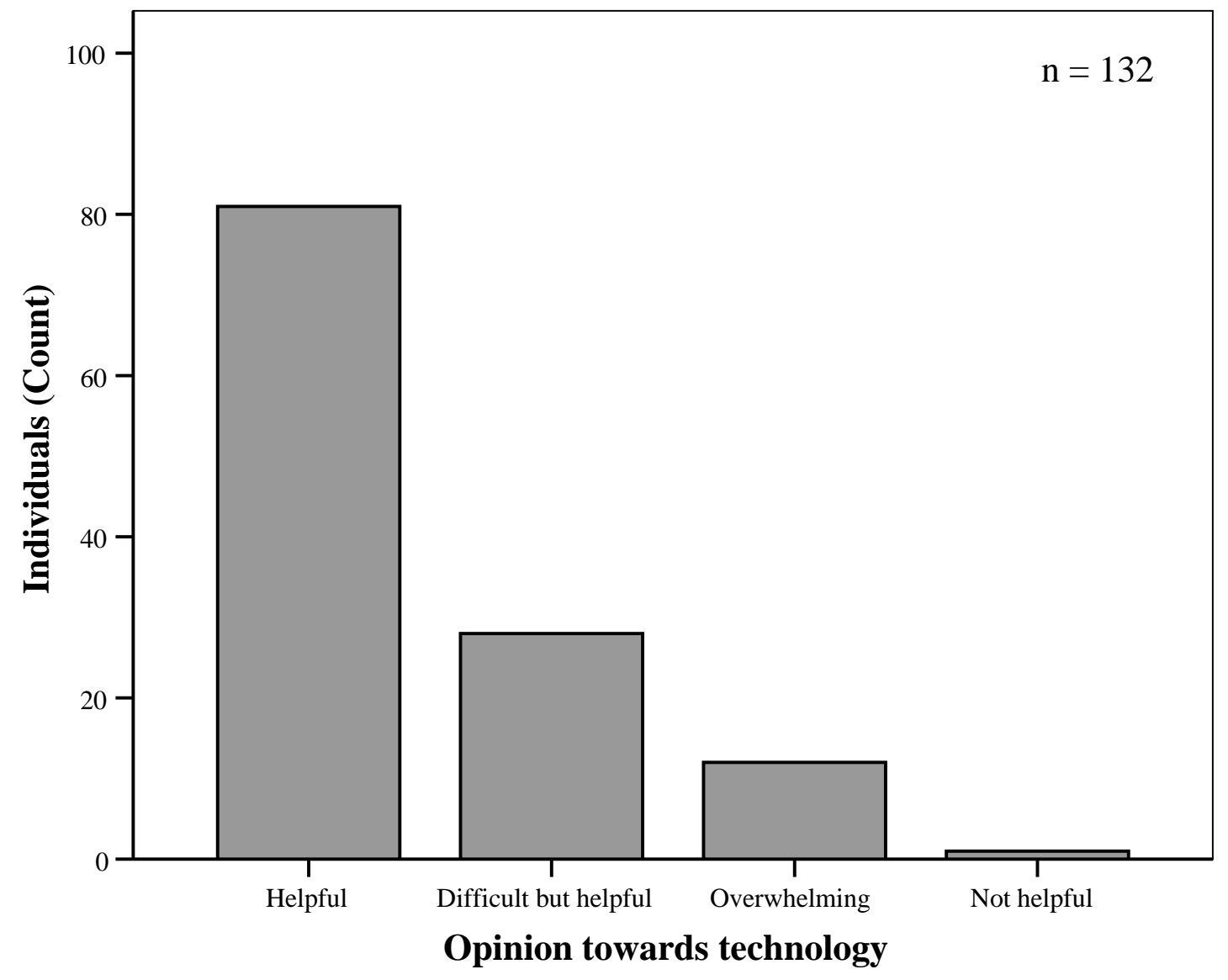


Figure 3. Interest toward technology

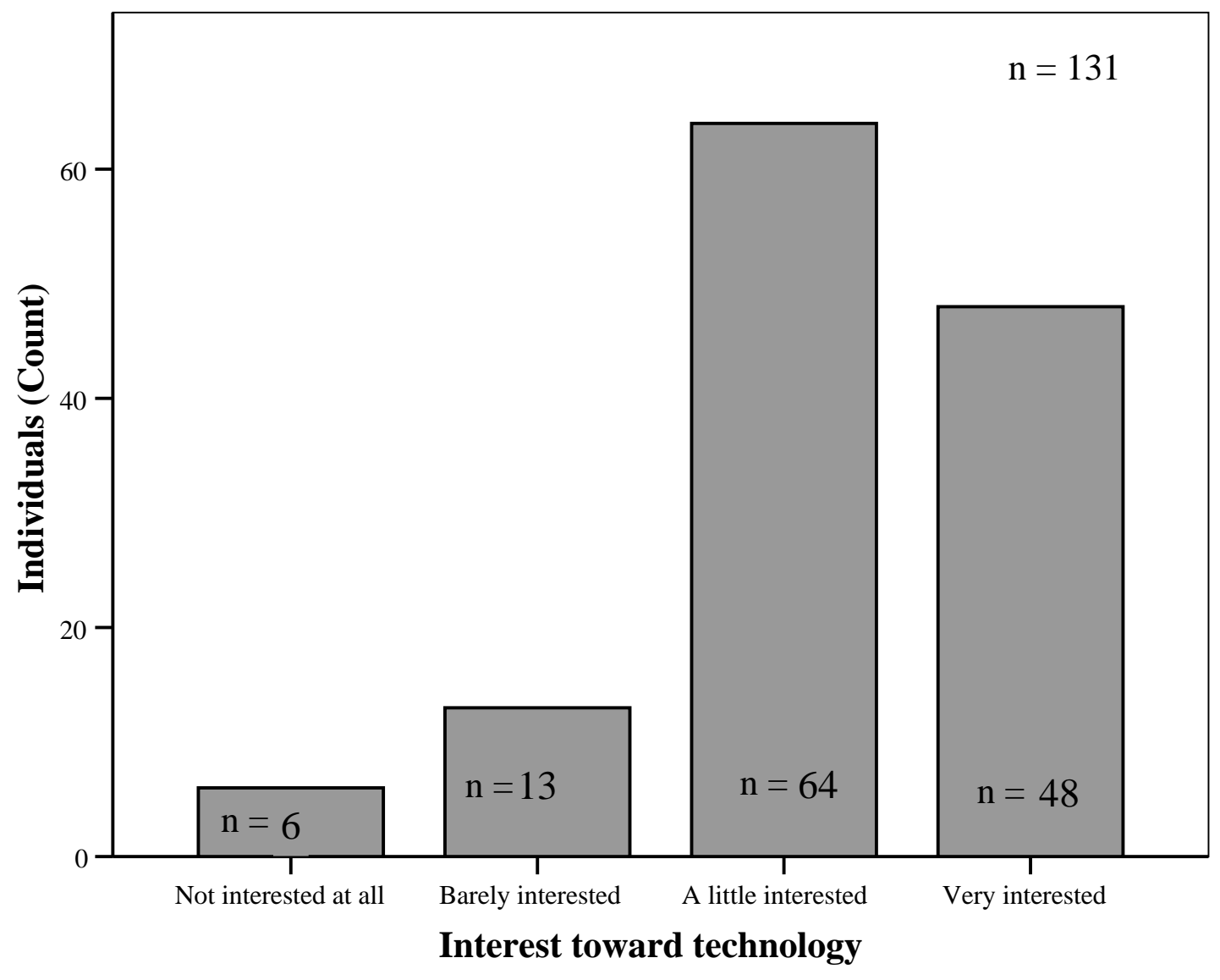


Figure 4. Computer training

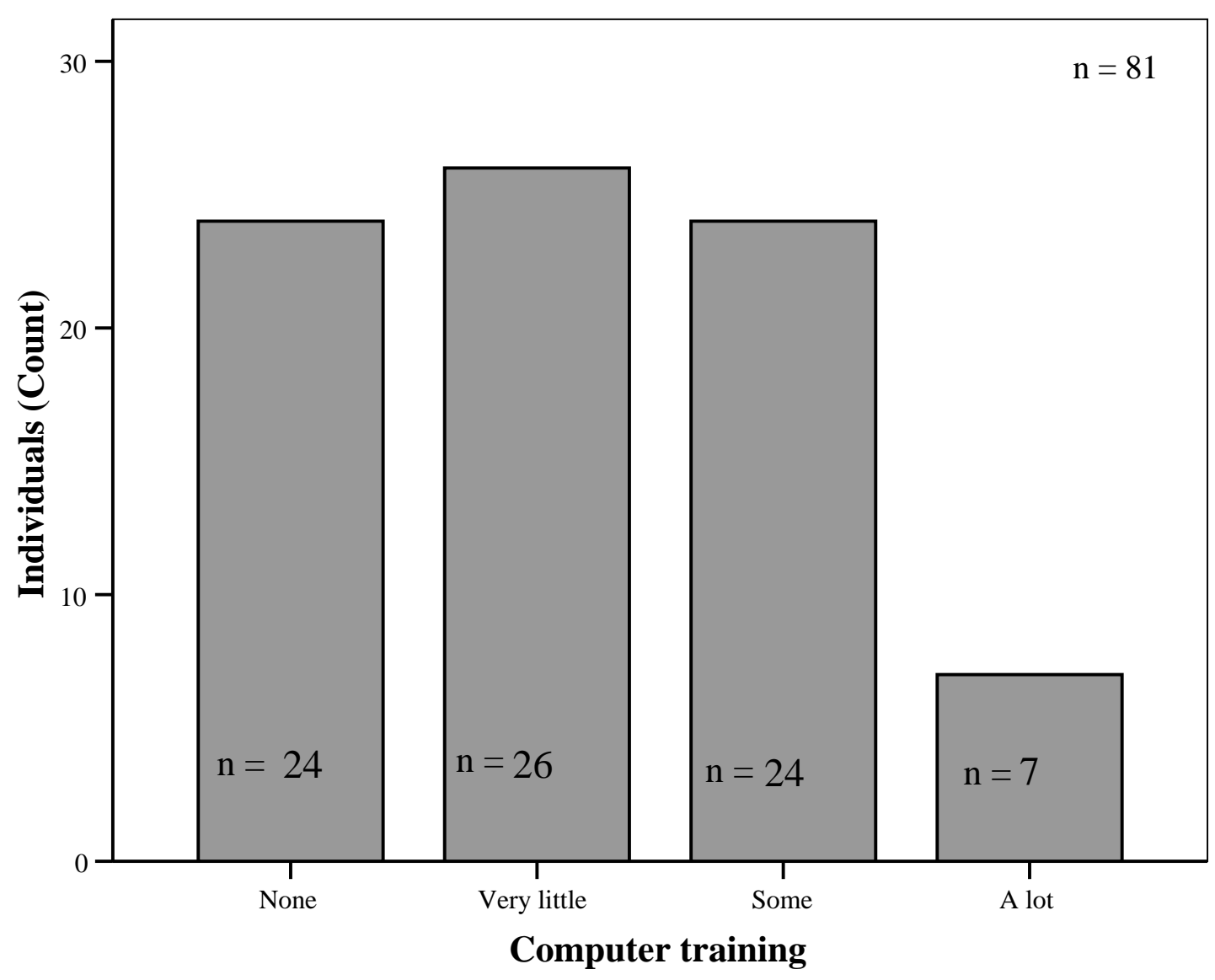


Figure 5. Willingness to learn technology

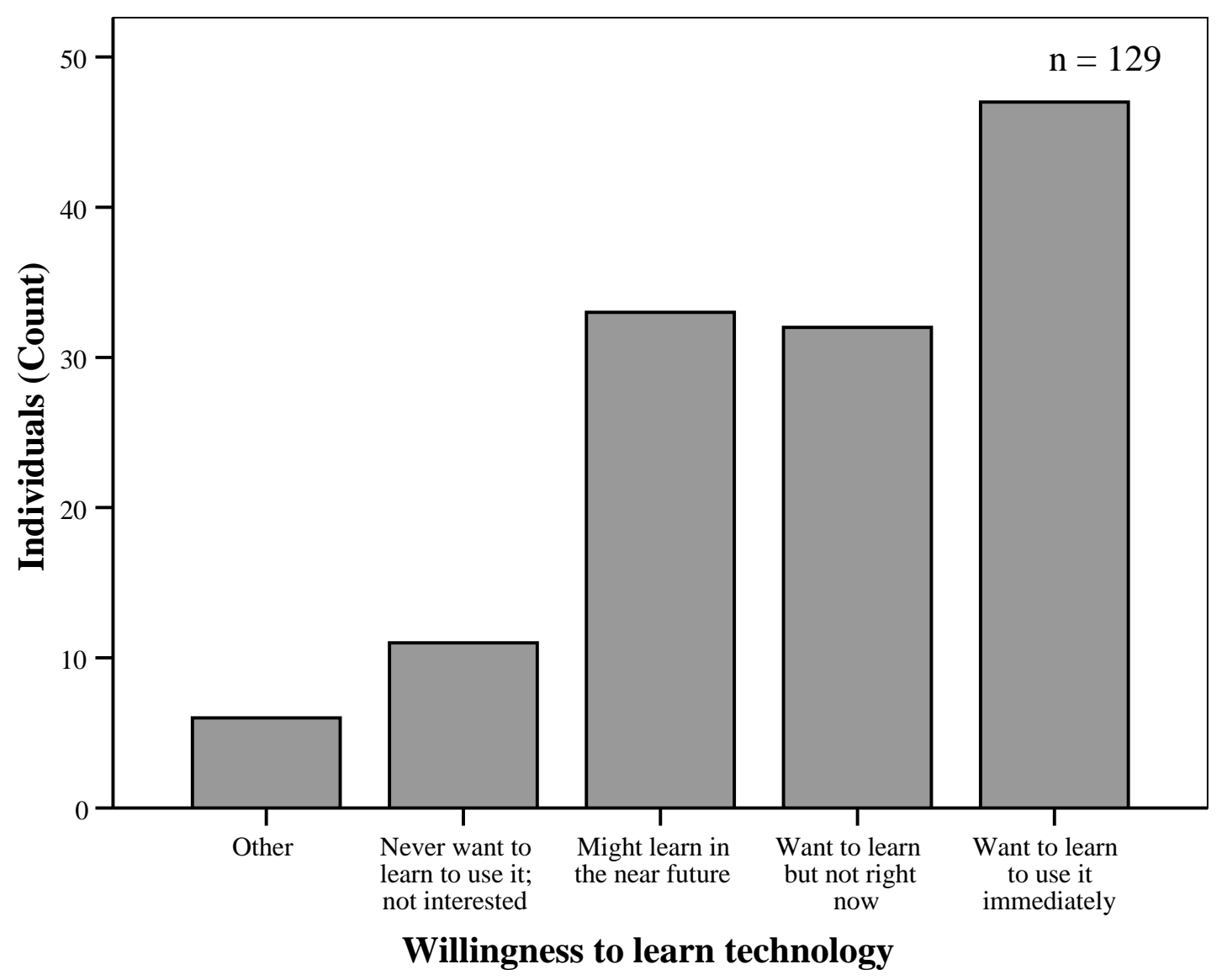


Figure 6. Nutrition and health topics of interest among the study population

\begin{tabular}{|ll|}
\hline - & Antioxidants \\
- & Arthritis \\
- & Calcium/bone density \\
- & Cancer \\
- & Cholesterol/diets \\
- & Diabetes/diets \\
- & Food safety \\
- & General nutrition information \\
- & Gracemic index \\
- & Healthy eating \\
- & Heart disease \\
- & Hypertension \\
- & Low carb foods \\
- & Macular Degeneration \\
- & Organic foods \\
- & Recipes \\
- & Staying healthy in old age \\
- & Sugar free foods \\
- & Supplements \\
- & Trans fats \\
- & Weight loss/control \\
\hline
\end{tabular}

Bolding represents top five topics selected by participants 
APPENDIX 1

IRB APPROVAL 


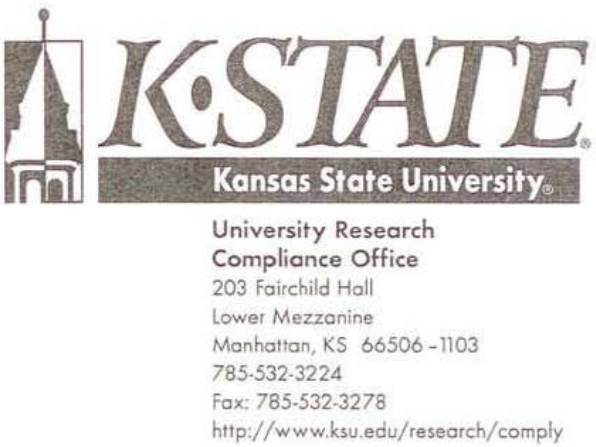

TO: Valentina Remig

Proposal Number: 4082

Human Nutrition

206 Justin Hall

FROM: Rick Scheidt, Chair

Commitiee on Research Involving Human Subjects

DATE: October 26, 2006

RE: Proposal Entitled, "Older adults' preferences for technological nutrition education"

The Institutional Review Board (IRB) for Kansas State University has reviewed the proposal identified above and has determined that it is exempt from further review.

This exemption applies only to the proposal currently on file with the IRB. Any change affecting human subjects must be approved by the IRB prior to implementation and may disqualify the proposal from exemption.

Exemption from review does not release the investigator from statutory responsibility for obtaining the informed consent of subjects or their authorized representatives, as appropriate, either orally or in writing, prior to involving the subjects in research. The general requirements for informed consent and for its documentation are set forth in the Federal Policy for the Protection of Human Subjects, 45 CFR 46.116-117, copies of which are available in the University Research Compliance Office and online at http://ohrp.osophs.dhhs.gov/humansubjects/guidance/45cfr46.htm\#46.116. In cases of remote oral data collection, as in telephone interviews, oral consent is sufficient and the researcher is required to provide the respondent with a copy of the consent statement only if the respondent requests one. The researcher must, however, ask the respondent whether he or she wishes to have a copy. The initiative in requesting a copy must not be left to the respondent. Regardless of whether the informed consent is written or oral, the investigator must keep a written record of the informed consent statement, not merely of the fact that it was presented, and must save this documentation for 3 years after completing the research.

The identification of a human subject in any publication constitutes an invasion of privacy and requires a separate informed consent.

Injuries or any unanticipated problems involving risk to subjects or to others must be reported immediately to the Chair of the Committee on Research Involving Human Subjects, the University Research Compliance Office, and if the subjects are KSU students, to the Director of the Student Health Center. 
APPENDIX 2

INFORMED CONSENT FORM 


\section{Number}

\section{Statement of Informed Consent Older Adults' Preferences For Technological Nutrition Education}

\section{Purpose of the Study}

This study will help identify the methods that older adults prefer to use for learning about nutrition and it will describe opinions/attitudes about technology.

I understand that this study is being performed by people from Kansas State University in the Department of Human Nutrition, and I agree to take part in this research.

This study will identify methods of learning about nutrition and attitudes toward technology. I understand that no medical procedures nor risks are involved. I will read or be asked (by a trained interviewer) a series of questions. I will answer as honestly and clearly as I can. Replying to the questionnaire will take about 15 minutes of my time. My participation is completely voluntary and I will not receive payment for my time. I also understand that I may stop participating or refuse to answer any question at any time without penalty or loss of benefits to which I may be entitled.

I understand that all my answers to the questions will be kept private and confidential. No information will be reported in any way that may identify me personally.

My signature below indicates that I have read and understand this consent form, and my signature acknowledges that I have received a signed and dated copy of this consent form for my reference.

If I have any questions about this study, I may contact:

Dr. Valentina Remig, Department of Human Nutrition

Kansas State University, 206 Justin Hall, Manhattan, KS 66506-1407

Phone number: (785) 532-0172 Email address: remig@ ksu.edu

Dr. Rick Scheidt, Chair of the Institutional Review Board

University Research Compliance Office (URCO), Kansas State University

Room 1 Fairchild Hall, Manhattan, KS 66506 Phone: (785) 532- 3224.

Name (please print) Date

Signature

Interviewer Signature

Date 
APPENDIX 3

\section{QUESTIONNAIRE}




\section{Number}

Date

\section{Older Adults' Preferences For Technological Nutrition Education Department of Human Nutrition - Kansas State University}

\section{Instructions:}

Please answer all the questions on this form carefully and select the option that best describes your situation and/or opinion. The first section will be about your experiences with computers and technology, followed by other questions about attitude, barriers, your health, and descriptors about you.

All of your replies will be kept confidential and will not be identified with your name.

1. Are there any nutrition topics or issues that are of particular interest to you?

Yes No

2. If you answered yes to the previous question, please list those topics of particular interest

Topics:

3. Have you ever used the computer to seek out information on that (or any other) nutrition topic?

Yes No

Which topics?

4. Are you a computer user for any purpose?

Y Yes No (if NO, omit next questions \# 5-7)

5. About how often do you use a computer for any purpose?

Every day
Once a week
Once a month
Once a year Only seasonally Never

6. Have you received any formal computer training or instruction to find information?

Yes

7. How much training have you received?

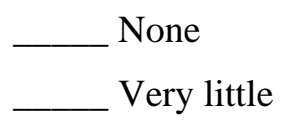

No

Some

A lot 
8. From the following list, identify which types of technology are familiar to you

TV
VCR
CD/DVD
Specific computer programs
Touch screen
Others

\section{Next, some questions about your attitudes toward "technology"}

9. In general, I feel that technology is:

Very helpful
Slightly helpful
Overwhelming
A little difficult to use but helpful
Not difficult to use
Not helpful at all
I don't use technology

10. Other types of technology that some people are using include:

$\begin{array}{ll}\text { ATM banking equipment } & \text { Cell phone } \\ \text { Video game } & \end{array}$

Do you use any of these? If so, please check the ones that you use

11. What is your overall interest toward technology?

Very interested

A little interested

Barely interested

Not interested at all

12. What is your willingness to learn about technology?

Want to learn to use it immediately

Want to learn but not right now

Might learn in the near future

Never want to learn or use it; not interested

Other

13. Is there one thing that you can identify that hinders your use of technology (computers and other types)? What hinders you?

Yes No 
14. Is there anything that would encourage you to use a computer and/or to use it more often?

Having access to a computer which is free of cost Receiving instruction/training

Programs that are simple to understand (user-friendly) Absolutely Nothing, I'm just not interested

15. From the following list, which factors influence your computer usage?

Lack of time

Convenience

Easy access

Where I live

Lack of access to computers

Lack of availability of computers

Economic issues

Others (please list)

The following questions will focus on ways which you use to learn about health and/or nutrition

16. What formats would you prefer to use to learn about health education?

$\begin{array}{ll} & \text { Personal interactions } \\ & \text { Newsletters } \\ \text { Brochures } & \\ & \text { Newspapers } \\ & \text { Magazines } \\ \text { Books }\end{array}$

17. From this list, which would be your most preferred format(s) for health education?

TV
Radio
Computer/Internet
Others (please list)

18. Where do you normally obtain health information?

Friends/relatives

Dietitian
Physician's office
Dentist's office
Magazines
Newspapers
Radio
TV
Computers/Internet




\section{Now, to complete this survey, a few questions about yourself:}

19. What is your gender?

Male

20. How old are you, what is your age in years?

(age in years)
Date of Birth:

Female

22. What do you consider to be your primary ethnicity? Single (never married) Divorced

21. What is your current marital status?

Single (never married)
Married
Widowed

Divorced
Separated
Engaged
White, not Hispanic Hispanic Black

Asian American Indian Other

23. How many years of education have you received? (please record actual number of years) years

24. What is your current working status? (please check "yes" or "no" for each option)

$\begin{array}{ll}\text { Yes/ No } & \text { Yes/ No } \\ \quad / \text { Employed full-time } & I \\ \quad / \text { Employed part-time } & \prime\end{array}$

25. How many persons are in your household?
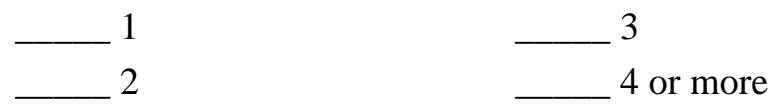

26. Now, for the income question which follows, please choose the group which best reflects your income situation (current income includes pensions, retirement, annuities, etc)

$<\$ 5,000$ (about $\$ 400 /$ month) $\$ 5,000-\$ 10,000$ (about $\$ 400-\$ 800 /$ month) $\$ 10,000$ - \$20,000 (about \$800-\$1,600/month) $\$ 20,000-\$ 30,000$ (about $\$ 1,600-\$ 2,500 /$ month) $\$ 30,000$ - $\$ 40,000$ (about $\$ 2,500-\$ 3,300 /$ month) $\$ 40,000$ or more (about $\$ 3,300$ or more/month) 


\section{These last questions are about your health}

27. How would you rate your overall physical health at this time?

$\begin{array}{ll}\text { Excellent } & \text { Fair } \\ \text { Good } & \text { Poor }\end{array}$

28. Do any of the following health issues concern you?

High Blood Pressure
Heart Disease
Arthritis
Cataracts
Macular Degeneration

Diabetes
Kidney disease
Cancer
Liver disease
None of these

29. How would you describe your eyesight?

Excellent
Good

Fair Poor

30. How is your hearing?

$\begin{array}{ll}\text { Excellent } & \ldots \\ \text { Good } & \text { Fair }\end{array}$

31. How would you compare your health now, to how it was 5 years ago?

$\begin{array}{ll}\text { Better } & \text { Worse } \\ \text { About the same } & \text { Not sure }\end{array}$

32. How would you describe your overall satisfaction with life in general at this time?

Excellent
Good
Fair

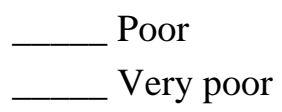

We have finished all of the items planned for the interview. Is there anything else that you would like me to know?

Yes (please record)
No

Thank you for sharing your time and opinions about these topics ! 